\title{
The Representation of Gender in a Textbook Entitled When English Rings a Bell
}

\author{
Fenty Lidya Siregar', Henni², Silvanni Comara³ \\ Universitas Kristen Maranatha, Indonesia \\ Email: fenty.siregar@outlook.com¹
}

Submitted: 03/05/2020

Revised: 08/01/2021

Accepted: 17/01/2021

$\begin{array}{ll}\text { E-ISSN : } 2579-4574 & \text { P-ISSN : 2549-7359 }\end{array}$

\begin{abstract}
Despite countless criticism that English textbooks contain gender biases, teachers still use textbooks in their teaching. This study investigated the representation of gender in an English textbook for junior high school level: When English Rings a Bell. Halliday's transitivity system (Halliday \& Matthiessen, 2004, 2014) is applied in this qualitative study to reveal how gender is represented. The result shows female characters dominate the roles of Participants. Regarding the types of Processes, the depictions of male and female characters are both significant in Relational processes; however, female characters are more frequently represented than male characters in other Processes. It is observed that both males and females are mostly attributed with positive personality adjectives. Only a few male characters are associated with negative traits. This study is expected to provide teachers and book authors with references of gender representations in the textbook so they can be aware of the imbalance and actively contribute to lessen this discrepancy.
\end{abstract}

Keywords: Textbook, gender representation, English, ideology

\section{https://ojs.unm.ac.id/eralingua}

This work is licensed under a Creative Commons Attribution-NonCommercial 4.0 International License 


\section{INTRODUCTION}

In the education field, the interconnection between language and gender is usually studied by investigating textbooks which are believed to be essential for its role as a guidance in the process of learning. According to Kereszty (2009) textbooks represent the quotidian world; therefore, they might significantly influence children's attitudes, behaviour, as well as their values, and behaviour given the fact that children frequently use textbooks in their learning. Widdowson (1990) argues that textbooks for foreign language learning usually consist of systemic and schematic knowledge. The former contains the formal properties of languages including syntax and semantics. The latter refers to the cultural environment aspects acquired from how the world is seen by L1 of the foreign language. In other words, not only do textbooks provide a linguistic background, but they also hold a central role in constructing ideology and stereotypes in the social world.

Many studies show that English teachers need textbooks for their teaching; however, not a few of the English textbooks still contain stereotypical images of men and women (Gharbavi \& Mousavi, 2012; Lee \& Collin, 2008; Mukundan \& Nimehchisal, 2008). The gender biases come in many forms such as in the use of lexical items that show actions and attributes. Males are usually portrayed as those who can do physical activities; or other actions that need thoughts and consideration. Whereas females are depicted as those who are passive or do actions that demand less energy (Emilia et al., 2017, p. 212). In the use of attributes, previous research projects show that females are shown to be weaker and more emotional compared to men (Barton \& Sakwa, 2012; Lee, 2014). This situation is also observable in the context of Indonesia. The study of Emilia et al., (2017, p. 212) found that female characters were described as "thoughtful", "anxious" and "expressive" but male characters were depicted as "rational", "powerful" and "individual". Gender bias can also be seen in the attributes that show occupations. Most textbooks used outside Indonesia still follow the traditional society by linking professions such as judge, doctor, and military officer to men and occupations such as nurse or teacher to women (Hall, 2014; Ullah \& Skelton, 2013). The same trend is also seen in Indonesia, as there were several studies which show that women were underrepresented in some occupations such as doctors and soldiers (Ena, 2013; Salamah, 2014). The results of past research project on gender representation show that continual assessment of gender representation in textbooks is essential so that English teachers will always be informed about gender bias in textbooks. It is hoped that when the teachers are aware of the bias, they can contribute to lessen this discrepancy.

Most of the previous studies use visual analysis to uncover gender bias in textbooks; however, the study of Emilia et al. (2017) used transitivity system of functional grammar (Halliday \& Matthiessen, 2004; 2014) to unpack gender stereotypes. Transitivity in systemic functional grammar serves the ideational metafunction, in which lexico-grammatical elements can be analysed to reveal how the language users represent their experience about the world. Despite much attention that gender representation has garnered in other countries all around the 
world, it has not been researched extensively using transitivity in Indonesia except for the study of Emilia et al. (2017). As a result, more rigorous studies need to be conducted.

With that in mind, this study examine how genders are represented in an English textbook entitled When English Rings a Bell (the fourth edition) by applying transitivity analysis to reveal whether or not gender equality presents. No study has specifically examined the fourth edition of the book on the topic of gender representation using Transitivity Analysis (processes, participants and circumstances). A previous study of Salsabil (2014) examined the first edition of the book using Transitivity Analysis; however, she did not investigate gender representation in the textbook. That leaves a gap to fill. Thus, the research question is as follows:

What are the processes, participants and circumstances observed in the textbook and what do they reveal about the gender-related ideology embedded in the textbook?

The answers of the research question are expected to provide references for junior high school English language teachers about the gender representation in the examined textbook as well as giving authors constructive feedback regarding how they present the female and male characters so that they can make some improvement to their textbook.

\section{LITERATURE REVIEW}

\section{Gender versus Sex}

According to Butler (1999), gender should be differentiated from sex considering that gender is produced performatively as an entity which is constructed and controlled by social values. The main principle that differs gender from sex is that the former is considered socially constructed; while the latter is considered a biological or physiological trait. The construct of gender is also multilayered and fluid, while the construct of sex is fixed and biological (Charteris-Black \& Seal, 2010). It means that social and cultural contexts affect the construct of gender but not the construct of sex.

Being socially constructed, gender brings with it several categorizations of males and females, which attribute different genders with different roles. Hence, there are two concepts: femininity and masculinity, which consist of ideas and practices that govern the behaviour of each gender (Holmes, 2009). The society is responsible for the shaping of this behaviour, through both informal and formal institutions. Media, schools, religious institutions, and the workplace play a significant role in this shaping. It is then formulated since the early age that girls and boys should dress differently, do different things, act in different ways; and when they become adults, they have different occupations. Unfortunately, the portrayal of girls and boys are never balanced. Boys and men are considered superior to girls and women (Holmes, 2009). 


\section{Transitivity, Gender and ideology}

Transitivity belongs to the ideational metafunction which recognises that clauses used in a text function as the representation of real-life experiences. Emilia et al. (2017) argue that transitivity can become the resource to interpret terms of processes, such as being, becoming, happening and doing. The system of transitivity of the English language contain: Process, Participants and Circumstances (Halliday \& Matthiessen, 2004). The Process itself consists of Material, Mental, Relational, Verbal, Behavioural and Existential (Halliday \& Matthiessen, 2014).

The system of transitivity is believed to have a function to uncover the ideological underpinnings of texts. (Mills, 1995) argues that when people are making utterances, they make a choice of processes and participants, and decide on what roles the participants should take. This is called transitivity choices. Therefore, analysing transitivity choices in texts can inform us how the authors place his or her textbook characters in the society, including how they construct the relation of the male and female characters. Knowles and Malmkjær (1996) argue that the ideology can either appear explicitly in the surface or be implicitly mentioned in the text through linguistic choices made by the writer. Thus, analysing the writer's choices, to be specific, their transitivity choices, can reveal how ideological views and power relationship of his or her characters are represented.

Very limited previous studies in Indonesia used transitivity to analyse English textbook employed at schools in the country. The study of Salsabil (2014) conducted Transitivity Analysis on the first edition of When English Rings a Bell for the first year of junior high school students. However, the study did not divide the characters based on gender and their roles as students, teachers, or other roles (such as parents, siblings, or friends) which is necessary in order to give a more thorough explanation regarding the textbook author's ideology on gender roles and equality. The study found that Relational Process is the highest process with 41.22\% frequency and Participants: Carrier, Attribute, Identified, and Identifier gain $42.59 \%$. Behavioral Process has the lowest frequency of occurrence $(0.68 \%)$ in the textbook. The characterized Circumstantial Element is Place-Location with the frequency of occurrence 55.51\%. Salsabil (2014) argues that the textbook consisted of descriptive texts and followed the guidelines of 2013 Curriculum.

Emilia et al. (2017) in their research on transitivity in two English textbooks for Indonesian students find that males appear in most of the Processes. Specifically, in the Material Process, it is found in the study that males tend to be portrayed doing actions that need more energy; thus, confirming the description of males as masculine (Emilia et al., 2017). However, females are found to do things which are more passive or demand less energy (Emilia et al., 2017). Females insignificantly outnumber males in Relational and Verbal Processes (Emilia et al., 2017). Yet, in terms of Relational Process, the diction used to describe males and females are still influenced by the stereotypes (Emilia et al., 2017). They argue that process type is the most significant element in distinguishing the involvement of males and females (Emilia et al., 2017). 


\section{Attributes and Gender Representation}

Adjectives and occupations are two attributes that often appear in English textbooks with clear-cut distinction between males and females. Different attributes are given for the physical appearances of males and females. Both studies of Lee (2014) and Ullah \& Skelton, (2013) find that women are usually labelled based on their attractiveness and although they are often portrayed through their physical shape, they are never described as muscular or strong like men. Females are commonly depicted as emotional and weak people (Barton \& Sakwa, 2012; Lee, 2014). In addition, Gray (2013) in his study of ten different EFL textbooks, finds that heterosexuality is always portrayed in the textbooks. It was observed that there were "short texts about gay figures" (p. 49), but homosexuality is not mentioned.

Another way to examine gender bias is to analyse how occupation is associated to males and females. Most textbooks still follow the traditional values maintained by society; depicting males to have prestigious and powerful occupations, for example as a judge, a doctor, or a military officer; while females are attributed with occupations with lower status, for example as a teacher, a nurse, or a receptionist (Hall, 2014; Ullah \& Skelton, 2013). A study done by Hall, (2014) on gender roles in two textbooks employed in Iranian secondary schools shows that men are portrayed in one of the textbooks to have more various jobs and overall the jobs have a higher status. Another finding shows that when males and females are dividing domestic chores, stereotype that household tasks such as cooking and cleaning still appears. Several studies on the division of domestic roles also show similar result (see Barton \& Sakwa, 2012; Ullah \& Skelton, 2013).

\section{RESEARCH METHOD}

\section{Research approach}

This study used a qualitative approach. Specifically the study was a qualitative descriptive analysis in order to uncover the portrayal of gender roles of the characters in the selected textbook. When the textual data is obtained, further investigation was carried by using the framework of Halliday's transitivity system of functional grammar (Halliday \& Matthiessen, 2004, 2014).

\section{Data and data sources}

This research project investigates a locally-published English language textbook entitled When English Rings a Bell (Wachidah et al., 2017) to know how the textual data represents women and men. This textbook is intended for junior high school students grade VII (12-14 years old). The chosen book contains 183 pages, which is divided into eight chapters. When English Rings a Bell has been chosen for the present study considering its functionality as a teaching material which is aimed at reaching the goals outlined in the Curriculum of 2013 (Ministry of Culture and Education of the Republic of Indonesia, 2013). The book analysed is the fourth edition which is in its electronic version (pdf format). As mentioned in the literature review, Salsabil (2014) has conducted Transitivity Analysis (Process Types, Participant Functions, and Circumstantial Elements) on the first edition of When English Rings a Bell for seventh grade students. However, she did not investigate 
gender representation in the textbook. The fact that the textbook has been revised and is still used in schools, while the new edition has not been investigated triggers the need to do the analysis. Therefore, this study aims to fill the gap by exploring how men and women are presented in the textbook.

\section{Data collection and analysis}

Regarding the data collection, to unpack how the textbook represents gender and to what extent the textbook maintains traditional gender roles or gender inequality especially in the use of process types and attributes, clauses from the textbook were gathered. Then, the researchers conducted the following analysis. Firstly, the analysis at clausal level was applied to the texts in order to find clauses which are gender-marked. Secondly, the presentation of a clause was investigated semantically under the concept of Processes (the action or process of material, mental, verbal, existential, relational, and behavioural), Participants (the role of those involved in the process, e.g. sayer, actor, goal and senser), and Circumstances (specify the when, how, where and why of the process, e.g. circumstance of location, manner, cause and contingency). The exploration of components, namely participants, processes and circumstances in the textual data in the textbook would help reveal how certain worldviews are framed as linguistic structures in the literary text (Fowler, 1986; Halliday, 1985).

The following are the examples of the analysis of transitivity patterns in the selected textbook:

\begin{tabular}{llc}
\hline He & Drinks & too much soft drinks \\
\hline Participant: actor (M) & Process: material & Participant: goal \\
\hline She & & (Wachidah et al., 2017, p.164) \\
\hline Participant: actor (F) & Process: material & Circumstance: time \\
\hline & & (Wachidah et al., 2017, p.161)
\end{tabular}

The participant was then labelled by a certain gender (male or female). Following the linguistic analysis, the data was investigated more deeply through an interpretation of associated gender roles. The transitivity analysis would highlight the representation of women and men in the textbook.

\section{FINDINGS AND DISCUSSION}

This section provides the findings and the discussion of the findings. The result of the data analysis which employed Transitivity system of SFL shows that the occurrences of male and female characters as Participants are seen in Material, Mental, Relational, Behavioural, Experiential, and Verbal processes (see Table 1) 
Tabel 1. The distribution of processes in analysed texts

\begin{tabular}{|c|c|c|c|c|c|c|c|c|c|c|}
\hline \multirow[b]{2}{*}{ PROCESS } & \multicolumn{3}{|c|}{ FEMALE } & \multicolumn{3}{|c|}{ MALE } & \multicolumn{3}{|c|}{ UNKNOWN } & \multirow[t]{2}{*}{ TOTAL } \\
\hline & $T$ & $S$ & 0 & $\mathbf{T}$ & $S$ & 0 & $T$ & $S$ & 0 & \\
\hline MATERIAL & 13 & 81 & 1 & 1 & 68 & 5 & - & - & 3 & 172 \\
\hline MENTAL & 8 & 54 & 2 & - & 39 & 8 & - & - & 4 & 115 \\
\hline RELATIONAL & 23 & 169 & 5 & 4 & 148 & 22 & - & 1 & 5 & 377 \\
\hline BEHAVIOURAL & - & 2 & - & - & 2 & - & - & - & - & 4 \\
\hline EXPERIENTIAL & - & 5 & - & - & - & - & - & - & - & 5 \\
\hline VERBAL & 3 & 22 & 6 & 2 & 10 & 5 & - & - & - & 48 \\
\hline TOTAL & 47 & 333 & 14 & 7 & 267 & 40 & 0 & 1 & 12 & 721 \\
\hline $\begin{array}{l}\text { TOTAL (per-group } \\
\text { \& percentage) }\end{array}$ & \multicolumn{3}{|c|}{$\begin{array}{l}394 \\
(54.64 \%)\end{array}$} & \multicolumn{3}{|c|}{$\begin{array}{l}314 \\
(43.55 \%)\end{array}$} & \multicolumn{3}{|c|}{$\begin{array}{l}13 \\
(1.81 \%)\end{array}$} & $\begin{array}{l}721 \\
(100 \%)\end{array}$ \\
\hline
\end{tabular}

First of all, Table 1 presents the distribution of processes. It can be seen that the kinds of process appearing in the characters, both males and females are quite similar. However, the number of processes with female teacher and student characters outnumbers males. On the other hand, in characters who are neither teachers nor students, the frequency of male characters is higher than the frequency of female characters in the six types, especially with regards to Relational process. Relational processes appear as the most prominent process in this study. This finding is similar to the study of Salsabil (2014) which investigated the previous edition of the same textbook. In her study she found that the highest process is held by Relational Process with more than $40 \%$ of the overall frequency. In the current study, the Relational Process takes $52.29 \%$ of the whole process types. Referring to the authors' considerable use of Relational processes, it can be argued that the textbooks attempts to depict who the characters are, what they are like and what they possess in a more straightforward manner. Example 1 and 2 exemplify the use of Relational processes using linking verbs, which dominates the texts written in the analysed textbook.

Example 1: He's tall (Wachidah et al., 2017, p.156)

Example 2: She's a beautiful slim girl (Wachidah et al., 2017, p.159)

Emilia et al., (2017) found that females outnumbered males regarding their role as Participants in the processes of Relational and Verbal. However, the overall findings of the current study reveal that females are more dominant than males, not only in the two processes as found in their study, but also in the other four processes. Thus, based on the overall of incidences in the study, females dominate the Participants component. It can imply that females are constructed as more powerful agents than males in the revised version of the book. 
Table 2. The distribution of participants in analysed texts

\begin{tabular}{|c|c|c|c|c|c|c|c|c|c|}
\hline \multirow[b]{2}{*}{ PARTICIPANTS } & \multicolumn{3}{|c|}{ FEMALE } & \multicolumn{3}{|c|}{ MALE } & \multicolumn{3}{|c|}{ UNKNOWN } \\
\hline & $T$ & $S$ & 0 & $\mathbf{T}$ & $S$ & 0 & $\mathbf{T}$ & $\mathbf{S}$ & 0 \\
\hline ACTOR & 13 & 81 & 1 & 1 & 68 & 5 & - & - & 3 \\
\hline GOAL & 13 & 81 & 1 & 1 & 68 & 5 & - & - & 3 \\
\hline RECIPIENT & - & - & - & - & - & - & - & - & - \\
\hline CLIENT & - & - & - & - & - & - & - & - & - \\
\hline INDUCER & - & - & - & - & - & - & - & - & - \\
\hline SCOPE & - & - & - & - & - & - & - & - & - \\
\hline SENSER & 8 & 54 & 2 & & 39 & 8 & - & - & 4 \\
\hline PHENOMENON & 8 & 54 & 2 & & 39 & 8 & - & - & 4 \\
\hline CARRIER & 23 & 169 & 5 & 4 & 149 & 26 & - & 1 & 5 \\
\hline ATTRIBUTE & 23 & 169 & 5 & 4 & 149 & 26 & - & 1 & 5 \\
\hline BEHAVER & - & - & - & - & - & - & - & - & - \\
\hline BEHAVIOUR & - & 2 & - & - & 2 & - & - & - & - \\
\hline EXISTENTIAL & - & - & - & - & - & - & - & - & - \\
\hline SAYER & 3 & 22 & 6 & 2 & 10 & 5 & - & - & - \\
\hline TARGET & - & - & - & - & - & - & - & - & - \\
\hline RECEIVER & 3 & 22 & 6 & 2 & 10 & 5 & - & - & - \\
\hline VERBIAGE & 1 & 11 & 6 & 1 & 4 & 4 & - & - & - \\
\hline Total & 95 & 665 & 34 & 15 & 538 & 92 & 0 & 2 & 24 \\
\hline \multirow[t]{2}{*}{ Total per-group } & \multicolumn{3}{|c|}{$794(54.19 \%)$} & \multicolumn{3}{|c|}{$645(44.02 \%)$} & \multicolumn{3}{|c|}{$26(1.79 \%)$} \\
\hline & \multicolumn{3}{|c|}{$1465(100 \%)$} & & & & & & \\
\hline
\end{tabular}

In line with the analysis of process types, in which Relational processes are found to be the most prominent, the analysis of participant functions indicates that female characters generally function as Carriers which are given certain attributive qualities or identities. Halliday and Matthiessen (2004) use the term "Attributive mode" to refer to those qualities.

At this point, another important aspect to discuss is lexical choice used to refer to certain gender. Based on a closer inspection of the Attributive mode, it has been discovered that the depiction of male and female characters is usually based on their individual characteristics. Nevertheless, in contrast with the finding of Emilia et al. (2017), the current study finds little difference in the lexical choice in the description of physical appearances and personal qualities of males and females since both characters are depicted positively. The findings indicate no stereotypical traits of masculine and feminine given to the characters in the textbook. However, although positive adjectives dominate the description of men and women in the textbook, it was observed that men are more frequently described using adverse traits, through the use of adjectives such as "smelly", "annoying" and "fussy", while there are no negative adjectives attached to female characters in textbook. The examples are as follow:

Example 3: She's very cute (Wachidah et al., 2017, p.147)

Example 4: She's very playful (Wachidah et al., 2017, p.147) 
Example 5: She's very kind and polite (Wachidah et al., 2017, p.122)

Example 6: She's clever, too(Wachidah et al., 2017, p.122)

Example 7: She is very patient (Wachidah et al., 2017, p.160)

Example 8: Look! Edo is very helpful (Wachidah et al., 2017, p.118)

Example 9: He is friendly to the neighbours (Wachidah et al., 2017, p.160)

Example 10: He is generous (Wachidah et al., 2017, p.164)

Example 11: Sometimes he is smelly (Wachidah et al., 2017, p.164)

Example 12: But sometimes he's annoying (Wachidah et al., 2017, p.163)

As shown in the above examples, most attributes attached to male and female characters are positive personality adjectives. A few instances of male characters' Attributive modes show that they are more likely to be described negatively. Despite the fact that females are represented in a more positive manner, men and women in the textbook are generally seen in good light, showing the authors' effort to give more positive characteristics rather than undesirable traits for both male and female characters. In other words, this indicates a sign of the authors' awareness of the significance of equally depicting male and female characters to avoid any unfavourable traits which may affect the learners negatively. It is also worth noting that different from the previous study of Emilia et.al (2017), which found that the occurrence of men is more frequent than the presence of women and that men are also depicted to hold more significant roles of Participants than women, the findings of the current study reveal the opposite result. This indicates the absence of male dominance over female, particularly in an educational environment such as a school.

Despite this absence, however, in the analysed textbook males are more likely to be represented in various occupational roles, compared to females, who are constantly portrayed as mainly students or teachers. This occurrence is especially noticed in clauses having Relational processes. The following are examples of a range of occupational roles ascribed to male characters in the textbook:

Example 13: He is a teacher (Wachidah et al., 2017, p.128)

Example 14: My father is a farmer (Wachidah et al., 2017, p.128)

Example 15: Pak Bacu is a janitor in our school (Wachidah et al., 2017, p.163)

Example 16: He is a good volleyball player (Wachidah et al., 2017, p.160)

The above examples illustrate how names of job serve to identify who the male characters are. Interestingly enough, males in the textbook appear to occupy more physical jobs, such as "farmer", "janitor" and "volleyball player", denoting a rather stereotypical view of men being more active and engaged in outdoor, physically demanding activities. Furthermore, example 17 and 18 reflect the types of career associated with female characters.

Example 17: She's a surgeon (Wachidah et al., 2017, p.128)

Example 18: She's a housewife (Wachidah et al., 2017, p.128)

Both examples show that, apart from being "teachers" and "students", female characters are also identified by other occupational roles, such as "surgeon" 
and "housewife". However, from these findings, it can be observed that the textbook presents a seemingly narrow portrayal of women in terms of social roles, considering that female characters are shown in fewer types of occupation. Emilia et al. (2017) argue that the high frequency of males implies the practice of dominator culture that commonly positions men as 'workers'. However, in this study the dominance of female teachers might indicate the stereotype of the female role as a person who has a role to nurture. As Drudy (2008, p. 135) argues, the 'domestic ideology' highlights men to be 'naturally' less disposed towards nurture than women. This ideology can negatively affect both females and males in terms of limiting their profession choice. Regarding the domination of male students, it might signify the portrayal of gender roles that men are more likely to go to school and be educated compared to women.

Table 3. The distribution of circumstance in analyzed text

\begin{tabular}{|c|c|c|c|c|c|c|c|c|}
\hline \multirow{2}{*}{$\begin{array}{l}\text { TYPES OF } \\
\text { CIRCUM- } \\
\text { STANCES }\end{array}$} & \multirow[b]{2}{*}{ SUB-TYPES } & \multicolumn{3}{|c|}{ FEMALE } & \multicolumn{4}{|c|}{ MALE } \\
\hline & & $\mathbf{T}$ & $\mathbf{S}$ & 0 & $\mathbf{T}$ & $\mathbf{S}$ & 0 & TOTAL \\
\hline \multirow{2}{*}{ Extent } & Distance & - & - & - & - & - & - & - \\
\hline & Duration & - & - & - & - & - & - & - \\
\hline \multirow{2}{*}{ Location } & Place & 2 & 13 & - & - & 9 & 17 & 41 \\
\hline & Time & 2 & 21 & 3 & 2 & 23 & 4 & 55 \\
\hline \multirow{3}{*}{ Manner } & Means & - & 1 & - & - & - & - & 1 \\
\hline & Quality & - & 3 & - & - & 6 & - & 9 \\
\hline & Comparison & - & 1 & - & - & - & - & 1 \\
\hline \multirow{6}{*}{ Cause } & Reason & - & - & - & - & - & - & - \\
\hline & Purpose & - & - & - & - & 1 & - & 1 \\
\hline & Behalf & - & 1 & - & - & - & - & 1 \\
\hline & Condition & - & - & - & - & - & - & - \\
\hline & Concession & - & - & - & - & - & - & - \\
\hline & Default & - & - & - & - & - & - & - \\
\hline \multirow{2}{*}{$\begin{array}{l}\text { Accompa- } \\
\text { niment }\end{array}$} & Comitative & - & - & - & - & - & - & - \\
\hline & Additive & - & 2 & - & - & - & - & 2 \\
\hline \multirow{2}{*}{ Role } & Guise & - & - & - & - & - & - & - \\
\hline & Product & - & - & - & - & - & - & - \\
\hline \multicolumn{2}{|l|}{ Matter } & - & - & - & - & - & - & - \\
\hline \multicolumn{2}{|l|}{ Angle } & - & - & - & - & - & - & - \\
\hline \multicolumn{2}{|c|}{ TOTAL (frequency) } & 4 & 42 & 3 & 2 & 39 & 21 & 111 \\
\hline \multirow{2}{*}{\multicolumn{2}{|c|}{ TOTAL (percentage) }} & 8.20 & 85.70 & 6.10 & 3.20 & 62.90 & 33.90 & 100 \\
\hline & & \multicolumn{3}{|c|}{$49(44.10 \%)$} & \multicolumn{3}{|c|}{$62(55.90 \%)$} & \\
\hline
\end{tabular}

Regarding the Circumstances, male characters appear to dominate the overall distribution (55.90\%). The prominent difference appears in clauses with circumstance of place and time portraying males as neither teachers nor students. Whereas the number of circumstance related to male teachers and students is less 
significant than female ones. The findings are different from the findings of Emilia et al. (2017) in which males outnumbered females in circumstantial features.

Although the type of Circumstances mostly associated with both male and female characters is the Circumstances of Time, this does not imply the representation of gender in the textbook. Gender representation is more observable in Circumstances of Place, in which both males and females are frequently described performing outdoors or in public sphere. This result is different from the results of Emilia et al. (2017), which find that compared to male characters, female characters are typically less active in public domain. The examples below are indicators of how the textbook under analysis has attempted to place both men and women in similar circumstances, namely public sphere or outdoors.

Example 19: He plays volleyball with our neighbours in the community centre every Saturday (Wachidah et al., 2017, p.160)

Example 20: On Sunday morning, I (female) usually go to the park with my family (Wachidah et al., 2017, p.44)

Example 21: She works at a bank (Wachidah et al., 2017, p.1)

There is an interesting feature in the book concerning gender representation. In the chapter about time and date, there is a table showing National Days in Indonesia (Wachidah et al., 2017). Below the table there is a dialogue between two female students talking about a date that is the Kartini Day, the day which is considered as the birth of gender equality in Indonesia. This may indicate the author's choice to foreground the idea that gender equality is something important in Indonesia.

However, some stereotypes on gender roles and attributes do appear. Apart from what has been mentioned above that the profession of a teacher is mostly associated to females, other occupations attributed to females are still related to the concept of nurture such as a housewife and a nurse. Another interesting occurrence is the setting of place depicted in the book when talking about rooms in the house. The setting of place where two female characters are having a dialogue is different from the male characters. The females are talking in a bedroom, which one can interpret as a more personal space, while the males are talking in the living room, which can be considered as a more social space. Moreover, a stereotype in terms of the attribute of colour is also shown. The female's bedroom has pink chairs and a red bed (Wachidah et al., 2017); whereas the male's living room has dark brown couch (Wachidah et al., 2017). The pink colour is also mentioned in another attribute related to a female character who is holding a pink purse Wachidah et al., 2017).

\section{CONCLUSION}

To conclude, in regard to Relational processes, the study found that the presence of men and women is significantly seen. This might be due to the fact that the topics discussed in the book deal with identities, characters' likes and preferences, and what the characters possess. It is also observed that both male and female characters are mostly attributed with positive personality adjectives, although males are sometimes associated with negative traits. Regarding the 
Circumstances, male characters are more dominantly described in clauses with circumstances than female characters; however, it only applies when the characters take a role as students. Female characters are dominant in the roles of Participants. The frequency of appearance of female teachers is higher than that of male teachers.

In terms of how gender-related ideology is represented in the textbook, the textbook seems to have put more female participants on display, although a traditional gender role in terms of occupation is still present. For instance, the dominance of female characters with regards to the Participant component indicates that in the revised version of the book, females are presented as more powerful agents than males. Furthermore, within the category of Circumstances of Place, both male and female characters perform activities outside the domain of private life. Male characters, however, are portrayed in a higher range of career domains since there are more various occupations for men than women. The unequal depiction of gender roles in the textbook somehow reflects the long-held conventional view of women in our society, where women are regarded as more capable when it comes to educating and nurturing. The biased representation can limit male students' worldviews and career choices as well as distorting their selfimage and the image of the opposite gender group. Consequently, teachers who use the particular book have to actively give a balance view of gender in their teaching and guide students to think critically about gender-related issues and gender stereotypes and actively try to lessen the bias through their actions.

Considering the powerful role of textbooks, especially in the beginning of schooling, it is critical to use textbook analysis in order to develop teaching materials which expose gender equality. Moreover, in a culturally and socially diverse country like Indonesia, textbook analysis would assist teachers in selecting materials covering cultural competence and promoting appropriate social values. On top of that, the interaction between teachers, students, and textbooks is dynamic. Therefore, there is a need for further research to fill this gap on how the interaction takes place and how gender is constructed in the classroom discourse

\section{REFERENCES}

Barton, A., \& Sakwa, L. N. (2012). The representation of gender in English textbooks in Uganda. Pedagogy, Culture \& Society, 20(2), 173-190. https://doi.org/10.1080/14681366.2012.669394

Butler, J. (1999). Gender trouble feminism and the subversion of identity. New York, NY: Routledge.

Charteris-Black, J., \& Seal, C. (2010). Gender and the language of illness. Basingstoke, England: Palgrave Macmillan.

Drudy, S. (2008). Gender balance/gender bias: The teaching profession and the impact of feminisation. Gender and Education, 20(4), 309-323. https://doi.org/10.1080/09540250802190156

Emilia, E., Moecharam, N. Y., \& Syifa, I. L. (2017a). Gender in EFL classroom: Transitivity analysis in English textbook for Indonesian students. Indonesian Journal of Applied Linguistics, 7(1), 206-214. https://doi.org/10.17509/ijal.v7i1.6877 
Emilia, E., Moecharam, N. Y., \& Syifa, I. L. (2017b). Gender in EFL classroom: Transitivity analysis in English textbook for Indonesian students. Indonesian Journal of Applied Linguistics, 7(1), 206-214. https://doi.org/10.17509/ijal.v7i1.6877

Ena, O. (2013). Visual analysis of e-textbooks for senior high school in Indonesia [Doctoral thesis, ProQuest Dissertations Publishing]. http://search.proquest.com/docview/1415874836/

Fowler, R. (1986). Linguistic criticism. Oxford University Press.

Gharbavi, A., \& Mousavi, S. A. (2012). A content analysis of textbooks: Investigating gender bias as a social prominence in Iranian high school English textbooks. English Linguistics Research, 1(1), 42-49. https://doi.org/10.5430/elr.v1n1p42

Gray, J. (2013). LGBT Invisibility and heteronormativity in ELT materials. In Critical Perspectives on Language Teaching Materials (pp. 40-62). Palgrave Macmillan.

Hall, M. (2014). Gender representation in current EFL textbooks in Iranian secondary schools. Journal of Language Teaching \& Research, 5(2), 253-261. https://doi.org/10.4304/jltr. 5.2.253-261

Halliday, M. A. K. (1985). An introduction to functional grammar. Edward Arnold.

Halliday, M. A. K., \& Matthiessen, C. M. I. M. (2004a). An introduction to functional grammar (3rd ed). Oxford University Press Inc.

Halliday, M. A. K., \& Matthiessen, C. M. I. M. (2004b). An introduction to functional grammar (3rd ed). Oxford University Press Inc.

Halliday, M. A. K., \& Matthiessen, C. M. I. M. (2014a). Halliday's introduction to functional grammar (4th ed). Routledge.

Halliday, M. A. K., \& Matthiessen, C. M. I. M. (2014b). Halliday's introduction to functional grammar (4th ed). Routledge.

Holmes, M. (2009). Gender and everyday life. Routledge.

Kereszty, O. (2009). Gender in textbooks. Practice and Theory in Systems of Education, $\quad 4(2), \quad 1-7$. https://scholar.google.com/scholar_lookup?title=Gender\%20in\%20textbooks \&author=0..\%20Kereszty\&journal=Practice\%20and\%20Theory\%20in\%20System s\%200f\%20Education\&volume=4\&issue $=2$ \&pages $=1-7 \&$ publication_year $=2009$

Knowles, M., \& Malmkjær, K. (1996). Language and control in children's literature. Routledge.

Lee, J. F. K. (2014). A hidden curriculum in Japanese EFL textbooks: Gender representation. Linguistics and Education, 27, 39-53. https://doi.org/doi:10.1016/j.linged.2014.07.002

Lee, J. F. K., \& Collin, P. (2008). Gender Voices in Hong Kong English textbooksSome past and current practices. Sex Roles, 59, 127-137. https://doi.org/10.1007/s11199-008-9414-6

Mills, S. (1995). Feminist stylistics. Routledge.

Ministry of Culture and Education of the Republic of Indonesia. (2013). 2013 Curriculum.

https://kemdikbud.go.id/kemdikbud/dokumen/Paparan/Paparan\%20Wamendi k.pdf 
Mukundan, J., \& Nimehchisal, V. (2008). Gender representation in Malaysian secondary school English language textbooks. Indonesian Journal of English Language Teaching, 4(2), 155-173. https://doi.org/10.25170\%2Fijelt.v4i2.149

Salamah, U. (2014). Gender representation in the English textbook: A content analysis of Bright for seventh grade students published by Erlangga [Undergraduate thesis, Syarif Hidayatullah State Islamic University]. http://repository.uinjkt.ac.id/dspace/bitstream/123456789/25777/3/UMMU\%20 SALAMAH-FITK.pdf

Salsabil, S. (2014). A transitivity analysis of English texts in Bahasa Inggris when English rings the bell [Undergraduate Thesis, Universitas Negeri Yogyakarta]. http://eprints.uny.ac.id/20432/1/Silvi\%20Salsabil\%2009202241067.pdf

Ullah, H., \& Skelton, C. (2013). Gender representation in the public sector schools textbooks of Pakistan. Educational Studies, 39(2), 183-194. https://doi.org/10.1080/03055698.2012.702892

Wachidah, S., Gunawan, A., Diyantari, \& Khatimah, Y. R. (2017). When English rings a bell. Kemendikbud.

Widdowson, H. G. (1990). Stylistics and the teaching of literature. Halow, UK: Longman. 